\begin{tabular}{|c|c|c|c|c|c|c|}
\hline \multirow{4}{*}{ Impact Factor: } & ISRA (India) & $=3.117$ & SIS (USA) & $=0.912$ & ICV (Poland) & $=6.630$ \\
\hline & ISI (Dubai, UAE & $=0.829$ & РИНЦ (Russia) & $=0.156$ & PIF (India) & $=1.940$ \\
\hline & GIF (Australia) & $=0.564$ & ESJI (KZ) & $=8.716$ & IBI (India) & $=4.260$ \\
\hline & JIF & $=1.500$ & SJIF (Morocco) & $=5.667$ & OAJI (USA) & $=0.350$ \\
\hline
\end{tabular}

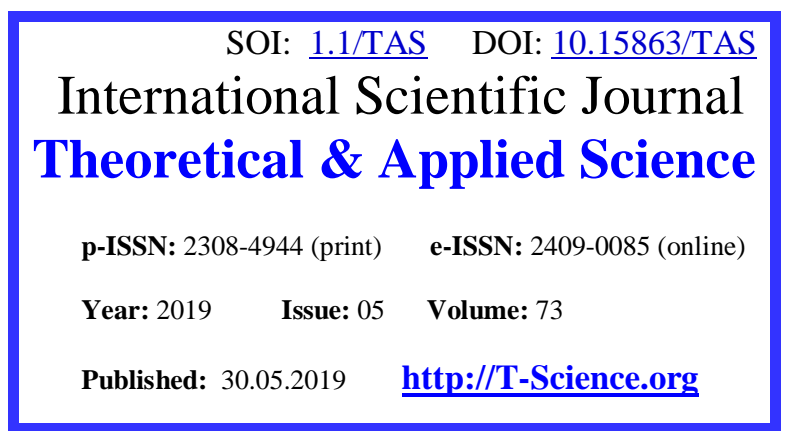

SECTION 4. Computer science, computer engineering and automation.
QR - Issue

QR - Article
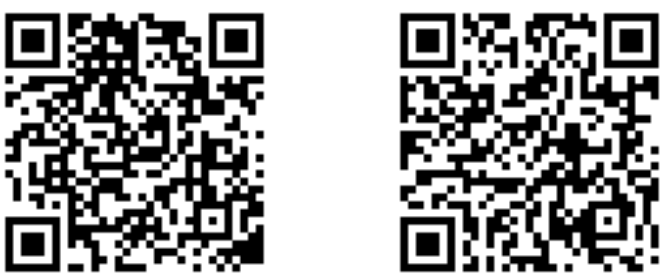

Pavel Aleksandrovich Vnukov bachelor

Peter the Great St. Petersburg Polytechic University vnukov95@gmail.com

Igor Nikolaevich Belyh

Peter the Great St. Petersburg Polytechic University, Associate Professor CIT, Ph.D.

\title{
RESEARCH OF SOURCES OF ALTERNATIVE ELECTRIC ENERGY AND METHODS OF THEIR JOINT WORK
}

Abstract: In this paper, we analyze the existing sources of alternative electricity, their advantages and disadvantages, as well as methods of their joint work.

Key words: alternative sources of electricity, collaboration, solar panels, wind turbines

Language: Russian

Citation: Vnukov, P. A., \& Belyh, I. N. (2019). Research of sources of alternative electric energy and methods of their joint work. ISJ Theoretical \& Applied Science, 05 (73), 601-605.

Soi: http://s-o-i.org/1.1/TAS-05-73-94 Doi: crosłef https://dx.doi.org/10.15863/TAS.2019.05.73.94

\section{ИССЛЕДОВАНИЕ ИСТОЧНИКОВ АЛЬТЕРНАТИВНОЙ ЭЛЕКТРОЭНЕРГИИ И МЕТОДОВ ИХ СОВМЕСТНОЙ РАБОТЫ}

Аннотация: В данной работе проводится анализ существующих источников альтернативной электроэнергии, их преимущества и недостатки, а также методы их совместной работы.

Ключевые слова: альтернативные источники электроэнергии, совместная работа, солнечные панели, ветрогенераторы.

\section{Введение}

На метеорологических станциях по всей территории Российской Федерации используется либо электричество от общей сети, либо дизельные или бензиновые генераторы. Проблема второго метода подключения в полной остановке станции в случае закончившегося топлива.

В условиях Крайнего Севера и других холодных регионов, здания станции питаются электричеством и обогреваются за счёт генераторов. В случае выхода из строя генератора или окончившегося топлива последствия для работников станции могут привести к гуманитарным проблемам, поскольку с отключением электропитания станция теряет связь с внешним миром, и теряется понимание о ее текущем состоянии.

Появляется высокая потребность в использовании альтернативных источников электроэнергии и анализе их совместной работы.
В своей работе я исследую варианты оптимизации совместной работы нескольких источников электроэнергии, привожу результаты испытания их одиночной и совместной работы.

По данным Enerdata [1] на 2017 год человечество потребляет примерно 24000000 ГВТ/ч. Из них 889000 ГВТ/ч потребляет Россия. В 2018 году доля альтернативных возобновляемых источников энергии (без крупных ГЭС) составила $8,4 \%$ в мировой генерации электричества. С учетом крупных ГЭС доля возобновляемых источников приближается к $24 \%$.

Рассмотрим существующие потенциальные источники альтернативной электроэнергии:

\section{Ветроэнергетика}

В ветроэнергетике используется преобразование кинетической энергии воздушных масс в атмосфере в электроэнергию [2]. 


\begin{tabular}{|c|c|c|c|c|c|c|}
\hline \multirow{4}{*}{ Impact Factor: } & ISRA (India) & $=3.117$ & SIS (USA) & $=0.912$ & ICV (Poland) & $=6.630$ \\
\hline & ISI (Dubai, UAE & $=0.829$ & РИНЦ (Russia & $=0.156$ & PIF (India) & $=1.940$ \\
\hline & GIF (Australia) & $=0.564$ & ESJI (KZ) & $=8.716$ & IBI (India) & $=4.260$ \\
\hline & JIF & $=1.500$ & SJIF (Morocce & $=5.667$ & OAJI (USA) & $=0.350$ \\
\hline
\end{tabular}

На 25 февраля 2019 года общая установленная мощность всех ветрогенераторов составила 600 гигаватт [3] и, таким образом, превзошла суммарную установленную мощность атомной энергетики

Наиболее перспективными местами для производства энергии из ветра считаются прибрежные зоны.

Ветрогенератор начинает производить ток при ветре $3 \mathrm{~m} / \mathrm{c}$ и отключается при ветре более 25 м/с. Максимальная мощность достигается при ветре $15 \mathrm{~m} / \mathrm{c}$ [4].

В большинстве регионов России среднегодовая скорость ветра не превышает $5 \mathrm{~m} / \mathrm{c}$, в связи с чем привычные ветрогенераторы с горизонтальной осью вращения практически не применимы - получить от их работы существенное количество энергии не удастся. Однако на сегодняшний день все больше производителей ветрогенераторов предлагают т. н. роторные установки, или ветрогенераторы с вертикальной осью вращения. Принципиальное отличие состоит в том, что вертикальному генератору достаточно $1 \mathrm{~m} / \mathrm{c}$ чтобы начать вырабатывать электричество [8].

Существуют следующие разновидности ветрогенераторов: наземные, прибрежные, шельфовые - на участке моря с небольшой глубиной, плавающие, парящие, горные.

\section{Гелиоэнергетика (солнечная энергетика)}

В гелиоэнергетике используется преобразование солнечного излучения в электроэнергию [2].

На 30 июля 2018 года общая установленная мощность всех солнечных панелей составила 471 гигаватта, что примерно на 15 процентов меньше мощности всех ветрогенераторов.

Особенности строения фотоэлементов вызывают снижение производительности панелей с ростом температуры.

Солнечная электростанция не работает ночью и недостаточно эффективно работает в вечерних сумерках.

В мире ежегодный прирост энергетики солнечных панелей за последние пять лет составлял в среднем около 50 \% [5]. Полученная на основе солнечного излучения энергия гипотетически сможет к 2050 году обеспечить $20-25 \%$ потребностей человечества в электричестве и сократит выбросы углекислоты.

Основные разновидности солнечных панелей: солнечные панели на основе фотоэлементов и солнечные панели на основе наноантенн (теоретические) [6].

\section{Геотермальная энергетика}

В геотермальной энергетике используется преобразование тепловой энергии недр Земли в электроэнергию [2]. Общая производимая мощность геотермальных электростанций составляет примерно 15 гигаватт.

Геотермальная энергия является самой перспективной в случае увеличения КПД преобразующих установок и обустройстве известных источников.

Схемы работы геотермальных станций:

- прямая схема - пар направляется по трубам в турбины;

- непрямая схема - пар предварительно очищается;

- бинарная схема - используется жидкость c низкой температурой кипения, которая нагревается за счёт теплообмена с термальным источником.

\section{Альтернативная гидроэнергетика}

В гидроэнергетике используется преобразование механической энергии приливов, волн, течений и тепловой энергии океана в электроэнергию [2].

Максимальные амплитуды приливовотливов характерны для окраинных морей умеренного климатического пояса. Наибольшими запасами приливной энергии обладают Атлантический океан и в меньшей мере Тихий океан.

Разновидности

альтернативных гидроэлектростанций: приливные, волноприбойные с турбинами, движимыми течением, моретермальные электростанции, мини и микро ГЭС.

\section{Методы совместной работы}

У каждого из альтернативных источников электроэнергии есть недостатки эффективности. Рассмотрим поподробнее каждый из них и возможности компенсации недостатков одного источника достоинствами других для оптимальной работы комбинированной системы в любой сезон и время суток.

Согласно данным метеослужб [7], средняя скорость ветра по регионам за год составляет приблизительно 3,8 метра в секунду. Преимущественно сильные ветра дуют в прибрежных и равнинных регионах. В зимнее время года порывы ветра статистически сильнее, чем в тёплое. Получается, у ветрогенераторов нет привязки к времени суток, но есть привязка к времени года.

Солнечные панели эффективнее всего работают в солнечную, но не сильно жаркую погоду. Также панели сильно теряют эффективность в ночное время.

Геотермальные источники универсальны и не зависят ни от времени суток, ни от сезона. 


\begin{tabular}{|c|c|c|c|c|c|c|}
\hline \multirow{4}{*}{ Impact Factor: } & ISRA (India) & $=3.117$ & SIS (USA) & $=0.912$ & ICV (Poland) & $=6.630$ \\
\hline & ISI (Dubai, UAE & $=0.829$ & РИНЦ (Russia & $=0.156$ & PIF (India) & $=1.940$ \\
\hline & GIF (Australia) & $=0.564$ & ESJI (KZ) & $=8.716$ & IBI (India) & $=4.260$ \\
\hline & JIF & $=1.500$ & SJIF (Morocce & $=5.667$ & OAJI (USA) & $=0.350$ \\
\hline
\end{tabular}

Приливные и прибойные электростанции останавливаются при замерзании водоёмов. ГЭС эффективнее всего работают в период паводков.

Основная проблема геотермальных и гидростанций в жесткой привязке к местоположению. Большинство метеорологических станций находится на большом расстоянии от возможных мест базирования электростанций.

Таким образом, в зависимости от местоположения станции, продолжительности светового дня и средней силе ветра, самым оптимальным вариантом будет комбинировать несколько ветрогенераторов с несколькими солнечными панелями. Таким образом, в дневное время эффективнее будут работать солнечные панели, ночью бесперебойность обеспечат ветрогенераторы и аккумуляторы. В зимнее время эффективнее будет работать ветрогенераторы, производительность выработки не должна сильно понижаться [9].

Для обеспечения максимальной автономности, в случае безветренной хмурой погоды или ураганного ветра, когда ветрогенераторы блокируются в целях безопасности, на станциях следует оставить бензо (дизель) генераторы [10].

\section{Испытание ветрогенераторов}

Испытание вертикальных ветрогенераторов проводилось в зимнее время на базе Архангельский ЦГМС-Р ФГБУ «Северное управление по гидрометеорологии и мониторингу окружающей среды». На рис.1 приведена зависимость выработки электроэнергии ветрогенератором от скорости ветра. Генерируемая мощность фиксировалась контроллером заряда аккумуляторных батарей. В качестве нагрузки использовался проволочный резистор с сопротивлением 100 Ом, мощность рассеивания 200 Вт. Контроллер заряда выдает среднее значение мощности за выбранный промежуток времени (в исследуемом случае 3 часа), скорость ветра фиксировалась мгновенная каждые 3 часа.

Испытания показали, что при скорости ветра 5-6 м/с ветрогенератор отдает 40-180 Вт, а при скорости ветра 3-4 м/с - 10-39 Вт. При меньшей скорости ветра ветрогенератор практически не вырабатывает электрической энергии. Архангельск относится ко 2 ветровому району с ветровой нагрузкой в 30 кг/кв.м. Поэтому ветер с высокой скоростью здесь бывает не часто.

Проанализировав метеорологическую сводку по Архангельску за год [7], можно заметить, что в холодное время года скорость ветра по среднему значению превышает скорость ветра по среднему значению в теплое время года, что говорит о большей эффективности системы ветрогенераторов в холодное время года.

Для улучшения эффективности работы ветрогенераторов требуется их размещение на открытых возвышенных участках либо на береговой зоне. Территорию для размещения обязательно нужно выбирать с помощью приборов для измерения скорости ветра (Анемометров).

\section{Испытание солнечных панелей}

Испытание солнечных панелей проводилось в летнее время на мысе Желания острова Новая Земля (Широта: $76^{\circ} 55,54^{\prime}$ Долгота: $\left.68^{\circ} 29,22^{\prime}\right)$. На рис.2 приведена зависимость выработки электроэнергии солнечными панелями от времени суток 27 июля 2018 года. Генерируемая мощность фиксировалась контроллером заряда аккумуляторных батарей. В качестве нагрузки использовался проволочный резистор с сопротивлением 100 Ом, мощность рассеивания 200 Вт.

Солнечные панели обеспечивают превышение порогового значения для заряда аккумуляторов в 80 Вт с 07:00 до 23:00. Заряда аккумуляторных батарей за это время достаточно, чтобы обеспечить станцию электропитанием в промежуток с 23:00 до 7:00. Проблема заключается в том, что солнечные батареи хорошо работают только около половины года с 22 марта по 21 сентября. В зимнее время выработка электроэнергии снижается. В районах за Полярным кругом может практически не вырабатываться.

Для улучшения эффективности работы солнечных панелей требуется их размещение на открытых возвышенных участках. Территория для размещения обязательно должна иметь максимальную освещенность на участке.

Объединение нескольких источников энергии в одну систему

Проанализировав особенности работы солнечных панелей и ветрогенераторов, можно заметить, что минусы одной системы практически полностью компенсируются плюсами другой. Соответственно, совместное использование двух источников энергии повысит общую стабильность и независимость системы.

На Архангельской базе в одну систему были объединены 2 ветрогенератора и 6 солнечных панелей. Ниже приведены результаты анализа системы.

В качестве нагрузки использовалась аппаратура радиосвязи станции. Контроллер заряда выдает среднее значение мощности за выбранный промежуток времени (в исследуемом случае 0,5 часа), скорость ветра фиксировалась мгновенная каждые 0,5 часа. На рис.3 приведена 


\begin{tabular}{|c|c|c|c|c|c|c|}
\hline \multirow{4}{*}{ Impact Factor: } & ISRA (India) & $=3.117$ & SIS (USA) & $=0.912$ & ICV (Poland) & $=6.630$ \\
\hline & ISI (Dubai, UAE & $=0.829$ & РИНЦ (Russia & $=0.156$ & PIF (India) & $=1.940$ \\
\hline & GIF (Australia) & $=0.564$ & ESJI (KZ) & $=8.716$ & IBI (India) & $=4.260$ \\
\hline & JIF & $=1.500$ & SJIF (Morocce & $=5.667$ & OAJI (USA) & $=0.350$ \\
\hline
\end{tabular}

зависимость выработки электроэнергии гибридной системой от скорости ветра. По показаниям видно, что гибридная система большую часть времени суток обеспечивает требуемую номинальную мощность в 107,6 Вт, но не может обеспечить работу системы в максимальном режиме длительное время.
Мониторинг системы показал, что электроэнергии, производимой гибридной системой с помощью 2 ветрогенераторов и 6 солнечных панелей вполне достаточно для питания системы связи.

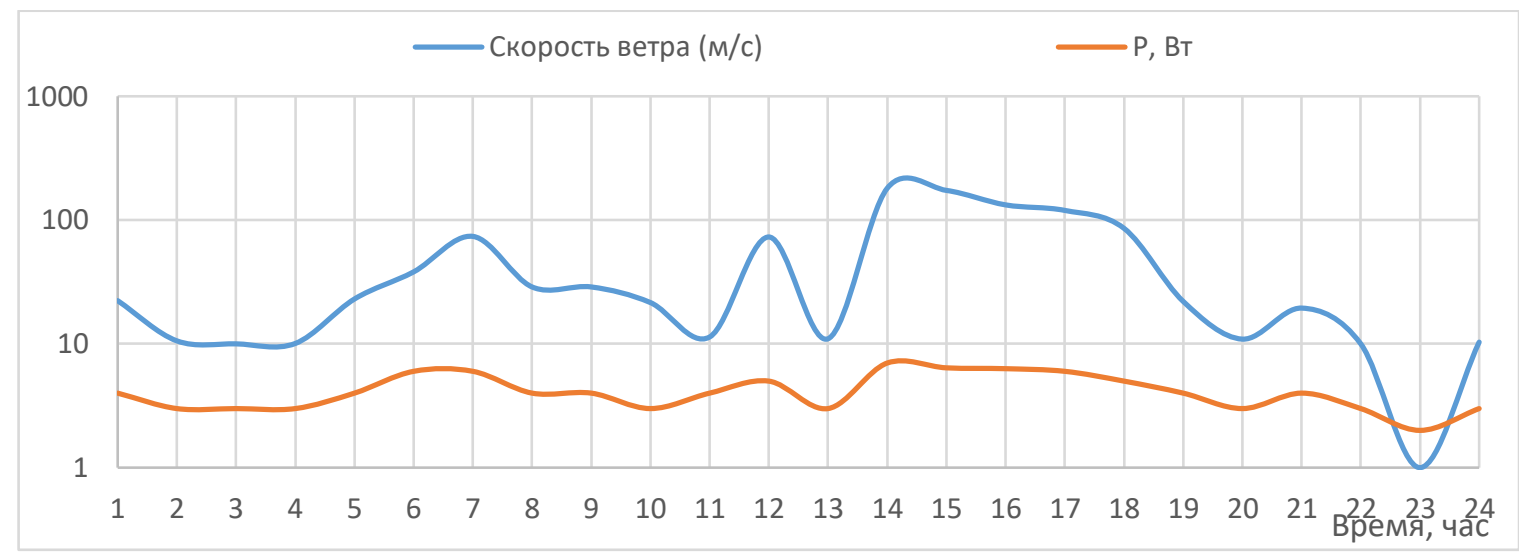

Рисунок 1. Зависимость выработки электроэнергии ветрогенератором и скорости ветра от времени суток.

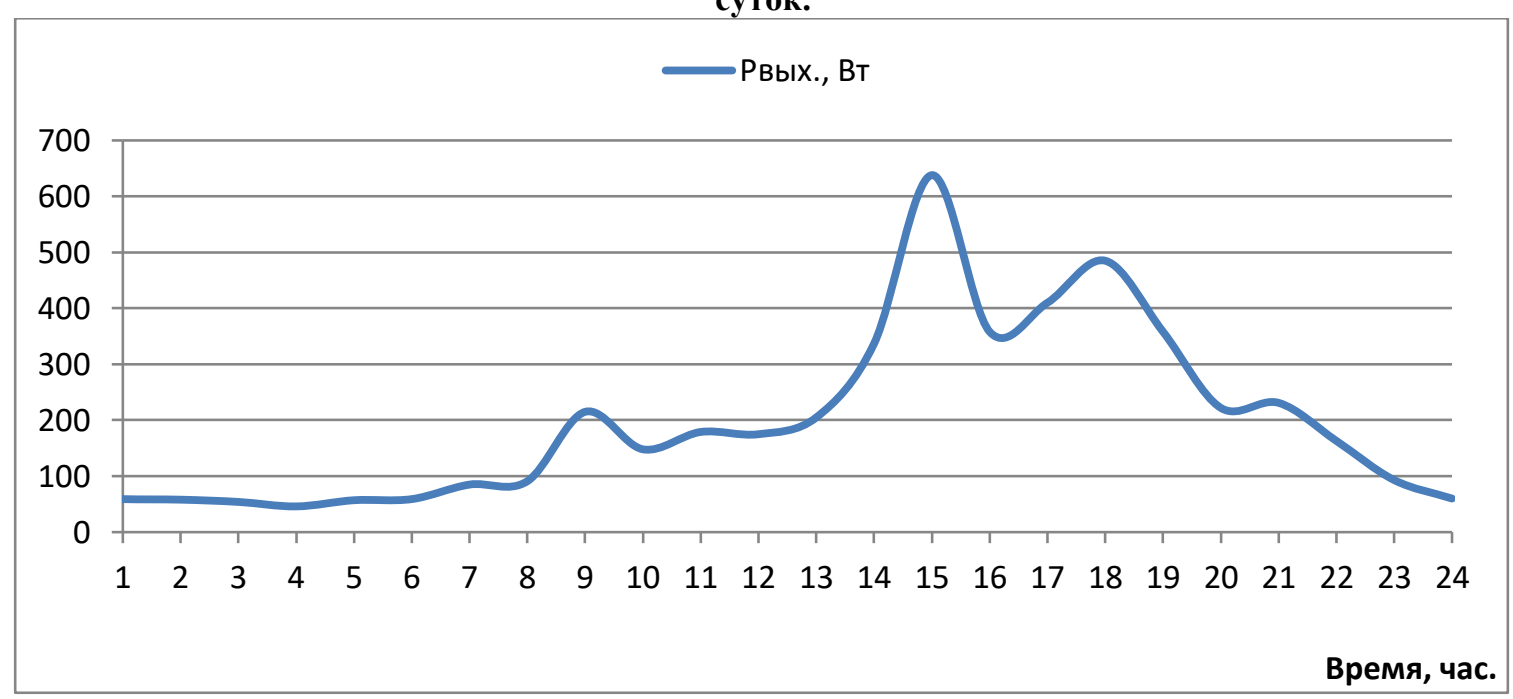

Рисунок 2. Зависимость выработки электроэнергии солнечными панелями от времени суток. 


\begin{tabular}{|c|c|c|c|c|c|c|}
\hline \multirow{4}{*}{ Impact Factor: } & ISRA (India) & $=3.117$ & SIS (USA) & $=0.912$ & ICV (Poland) & $=6.630$ \\
\hline & ISI (Dubai, UAE & $=0.829$ & РИНЦ (Russia & $=0.156$ & PIF (India) & $=1.940$ \\
\hline & GIF (Australia) & $=0.564$ & ESJI (KZ) & $=8.716$ & IBI (India) & $=4.260$ \\
\hline & JIF & $=1.500$ & SJIF (Morocce & $=5.667$ & OAJI (USA) & $=0.350$ \\
\hline
\end{tabular}

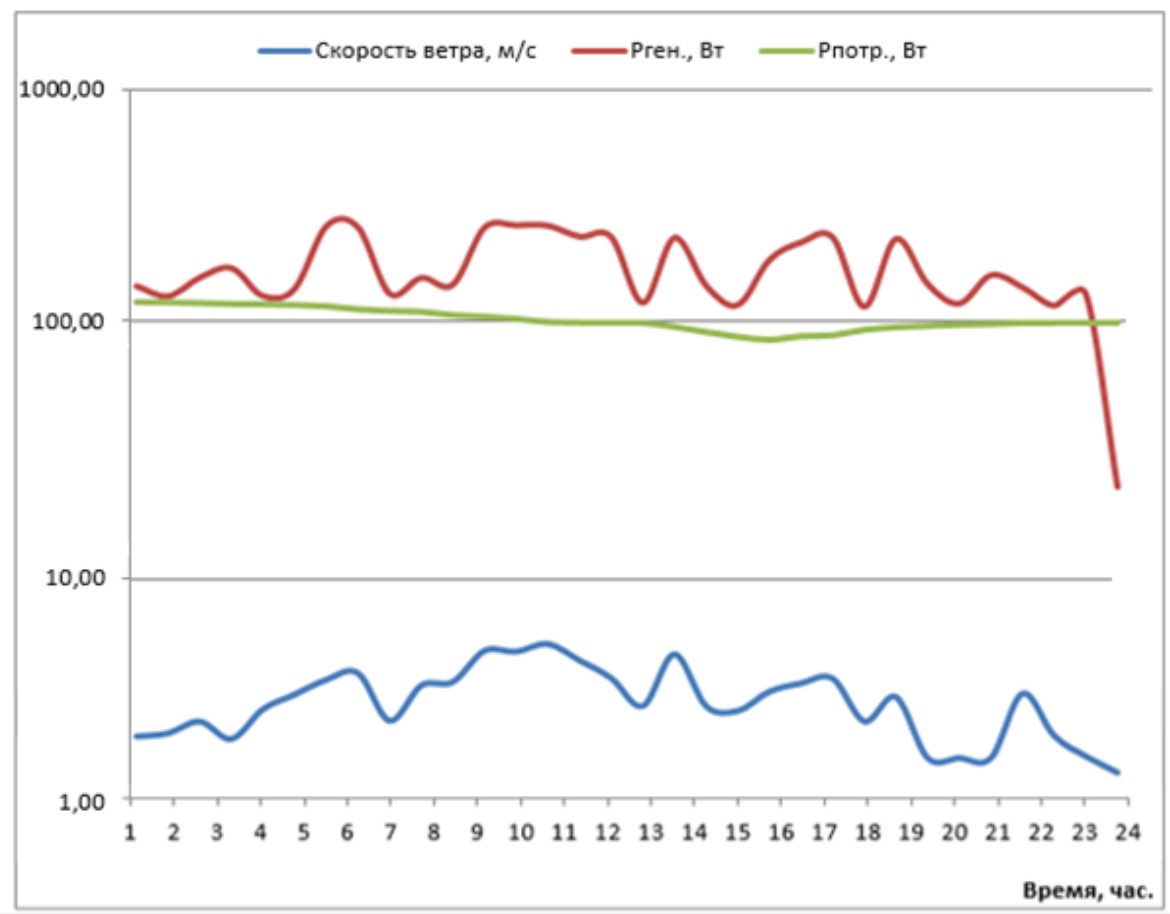

Рисунок 3. Зависимость выработки, потребления электроэнергии гибридной системой и скорости ветра времени суток

\section{Заключение}

Подведем итоги исследования. В ходе работы были исследованы альтернативные источники электрической энергии, выявлены их достоинства и недостатки. Также были получены результаты по комбинированию нескольких источников электроэнергии для оптимизации их совместной работы.

\section{References:}

1. (n.d.). Vnutrennee potreblenie elektroenergii. Retrieved June 1, 2019, from https://yearbook.enerdata.ru/electricity/electricit y-domestic-consumption-data.html

2. Alekseenko, S. V. (n.d.). Netraditsionnaya energetika. (pp.2004-2017). Moskva: Bol'shaya rossiyskaya entsiklopediya.

3. (n.d.). World Wind Energy Association - Wind Power Capacity Worldwide Reaches $600 \mathrm{GW}$, 53,9 GW added in 2018. Retrieved March 10, 2019 , from https://wwindea.org/blog/2019/02/25/windpower-capacity-worldwide-reaches-600-gw539-gw-added-in-2018/

4. Zubarev, V. V. (1982). Vetroenergetika. Moscow: Energoatomizdat.

5. Andrianov, V. N., Bystritskiy, D. N., Vashkevich, K. P., \& Sektorov, V. R. (1960). Vetroelektricheskie stantsii. (p.320). Moscow: Gosudarstvennoe energeticheskoe izdatel'stvo.
6. Nikitin, D. (n.d.). Trudnyy put' $k$ solntsu: sogreet li Rossiyu solnechnaya energetika. Retrieved May 15, 2019, from https://www.rbc.ru/economics/17/06/2013/8620 08.shtml

7. Korkish, R., Green, M., \& Patstser, T. (2003). Sbor solnechnoy energii antennami. Elsevier Science Ltd.

8. (n.d.). Skorosti vetra v Rossii - vetrogeneratory. Retrieved March 10, 2019, from http://www.vetrogenerator.ru/windtable.html

9. Sidorovich, V. (2015). Mirovaya energeticheskaya revolyutsiya: Kak vozobnovlyaemye istochniki energii izmenyat nash mir. (p.208). Moscow: Al'pina Pablisher.

10. Strunin, I. V. (2014). Obosnovanie skhemy parallel'noy raboty energeticheskikh ustanovok Moscow: Molodoy uchenyy. 